Citation: L. Soto-Muñoz, V. MartínezBlay, M.B. Pérez-Gago, A. FernándezCatalán, M. Argente-Sanchis, Lluís Palou (2021) Starch-glycerylmonostearate edible coatings formulated with sodium benzoate control postharvest citrus diseases caused by Penicillium digitatum and Penicillium italicum. Phytopathologia Mediterranea 60(2): 265-279. doi: 10.36253/phyto-12528

Accepted: March 16, 2021

Published: September 13, 2021

Copyright: $@ 2021$ Author. This is anopen access, peer-reviewed article published by Firenze University Press (http:// www.fupress.com/pm) and distributed under the terms of the Creative Commons Attribution License, which permits unrestricted use, distribution, and reproduction in any medium, provided the original author and source are credited.

Data Availability Statement: All relevant data are within the paper and its Supporting Information files.

Competing Interests: The Author(s) declare(s) no conflict of interest.

Editor: Pervin Kinay Teksür, Ege University, Bornova Izmir, Turkey.
Research Papers

\section{Starch-glyceryl monostearate edible coatings formulated with sodium benzoate control postharvest citrus diseases caused by Penicillium digitatum and Penicillium italicum}

\author{
LOURdes SOTO-MUÑOZ ${ }^{1,2, A}$, Victoria MARTÍNEZ-BLAY ${ }^{1, A}$, MARÍA \\ B. PÉREZ-GAGO ${ }^{1}$, Asunción FERNÁNDEZ-CATALÁN ${ }^{1}$, MARICruz \\ ARGENTE-SANCHIS ${ }^{1}$, Lluís PALOU ${ }^{1, *}$ \\ ${ }^{1}$ Laboratori de Patologia, Centre de Tecnologia Postcollita (CTP), Institut Valencià \\ d'Investigacions Agràries (IVIA), 46113 Montcada, València, Spain \\ ${ }^{2}$ Facultad de Química, Universidad Autónoma de Querétaro. Centro Universitario S/N, \\ Colonia Las Campanas, 76010 Querétaro, Mexico \\ ${ }^{A}$ L. Soto-Muñoz and V. Martínez-Blay contributed equally to this work as first authors. \\ *Corresponding author. E-mail: palou_llu@gva.es
}

\begin{abstract}
Summary. The curative antifungal activity of edible composite coatings (ECs) based on pregelatinized potato starch-glyceryl monostearate (PPS-GMS) formulated with or without sodium benzoate (SB) to control green mould (caused by Penicillium digitatum) and blue mould ( $P$. italicum) was assessed on 'Orri' mandarins, 'Valencia' oranges and 'Fino' lemons. These fruit were artificially inoculated with $P$. digitatum or P. italicum, treated by immersion in coating emulsions and compared to uncoated control fruit immersed in water and fruit immersed in $2 \% \mathrm{SB}(\mathrm{w} / \mathrm{v})$ aqueous solution. Treated fruit were then stored at either $20^{\circ} \mathrm{C}$ or commercial low temperature $\left(5^{\circ} \mathrm{C}\right.$ for mandarins and oranges, $12^{\circ} \mathrm{C}$ for lemons). Coatings without SB did not exhibit antifungal activity, whereas coatings containing $2 \% \mathrm{SB}$ reduced incidence and severity of green and blue moulds, in comparison to the controls, on all citrus species and in all storage conditions, without differing from the aplication of $2 \%$ SB alone. For example, incidence reduction on 'Fino' lemons was from 99 to $0 \%$ after $7 \mathrm{~d}$ at $20^{\circ} \mathrm{C}$, and from 99 to $30 \%$ after 2 weeks at $12^{\circ} \mathrm{C}$. None of the treatments was phytotoxic. These results indicate that applications of SB as antifungal ingredient of PPS-GMS based ECs is a promising non-polluting alternative to control Penicillium postharvest decay of citrus, and these ECs are effective substitutes for conventional waxes amended with synthetic fungicides.
\end{abstract}

Keywords. Green mould, blue mould, alternative disease control, antifungal fruit coatings, GRAS salts.

\title{
INTRODUCTION
}

Fungal pathogens are one of the main factors contributing to citrus spoilage and quality deterioration during postharvest fruit handling, leading to significant economic losses (Zacarias et al., 2020). Green mould (GM; 
see Table 1 for definitions of abbreviations used in this paper) and blue mould (BM), caused, respectively, by Penicillium digitatum (Pers.: Fr.) Sacc. and Penicillium italicum Wehmer, are the most important postharvest citrus diseases, particularly in Mediterranean climate regions. These fungi are strict wound pathogens that infect citrus fruit through rind injuries caused during harvest, transportation, and postharvest handling and commercialization (Palou, 2014; Smilanick et al., 2020).

Treatments with synthetic fungicides applied as aqueous solutions or added to waxes have been traditionally used to reduce postharvest citrus decay to commercially acceptable levels (Erasmus et al., 2013; Njombolwana et al., 2013). However, due to legislative restrictions and consumer trends, the citrus industry demands safer approaches to control postharvest diseases. Alternative control methods include different physical treatments, antimicrobial antagonists used as biocontrol agents, and low-toxicity chemicals classified as food additives or generally recognized as safe (GRAS) compounds. These compounds include organic and inorganic salts, chitosan, essential oils and other plant extracts (Moscoso-Ramírez et al., 2013; Palou et al., 2016; Palou, 2018; Papoutsis et al., 2019; Sapper et al., 2019).

Among the different disease management alternatives, GRAS salts present important advantages, including high water solubility, availability, and general low cost (Palou, 2018). Thus, their potential to control citrus postharvest decay as aqueous solutions or as ingredients of composite edible coatings (ECs) is an active research field (Palou et al., 2015; Montesinos-Herrero et al., 2016). The effectiveness of GRAS salts, including benzoates, bicarbonates, carbonates, metabisulfites, parabens, silicates, and sorbates, for control of major postharvest citrus diseases has been demonstrated in previous studies (Palou et al., 2002; Smilanick et al., 2008; Valencia-Chamorro et al., 2009a; Askarne et al., 2013; Moscoso-Ramírez et al., 2013; Youssef et al., 2014; Montesinos-Herrero et al., 2016; Guimarães et al., 2019; Martínez-Blay et al., 2020a; 2020b). We have found that, among these salts, aqueous solutions of sodium benzoate (SB) had substantial curative activity against citrus GM and BM (Montesinos-Herrero et al., 2016). Therefore, we have evaluated ECs containing this salt as an antifungal ingredient.

Since ECs on fruit act as water and gas barriers, the use of ECs formulated with antifungal GRAS ingredients allows coating the fruit directly with a thin layer of edible material to provide antifungal activity, maintain fruit physicochemical quality and extend shelf life (Janjarasskul and Krochta, 2010; Valencia-Chamorro et al., 2011a; Palou et al., 2015; Sapper and Chiralt, 2018). In addition, postharvest use of ECs containing GRAS compounds may facilitate slow diffusion of active ingredient from coating matrices, compared to application of aqueous solutions (Palou et al., 2015; Palou, 2018). We have previously demonstrated that ECs based on hydroxypropyl methylcellulose (HPMC) containing antifungal GRAS salts reduced brown rot in plums (Karaca et al., 2014; Gunaydin et al., 2017) and Alternaria black spot and gray mould in cherry tomatoes (Fagundes et al., 2013; 2015), while the physicochemical and sensory qualities of the fruit were maintained. Furthermore, on citrus fruit, these ECs controlled GM and BM (ValenciaChamorro et al., 2008; 2009a; 2009b; 2010; 2011b), Diplodia stem-end rot (Guimarães et al. 2019) and postharvest anthracnose (Martínez-Blay et al., 2020a), while fruit quality was preserved during cold storage. However, the effectiveness and stability of the ECs depended on their composition, and the incorporation of antifungal GRAS salts greatly changed the original coating matrix properties. This indicated the need to optimize the formulations for each target pathogen and fruit species or cultivar (Valencia-Chamorro et al., 2011a; Palou et al., 2015).

In addition to HPMC, starch has been reported as a promising polysaccharide for ECs due to its biodegradability, biocompatibility, availability and low cost, creating odourless, tasteless and transparent films with good fruit preservation properties (Acosta et al., 2015; Sapper and Chiralt, 2018). In addition, some studies have reported the antifungal activity of starch-based ECs amended with GRAS ingredients such as essential oils (Sapper et al., 2019), natamycin-cyclodextrin complex (Yang et al., 2019), biocontrol agents (Marín et al., 2016), lactic acid bacteria (Marín et al., 2019) and potassium sorbate (Mehyar et al., 2011) to control different postharvest diseases in apple, cucumbers, grapes, persimmon or tomatoes. However, no information is available regarding the utilization of GRAS salts as ingredients of starch-based ECs to control major citrus postharvest diseases. Considering the importance of factors such as coating composition (i.e., type of ingredients and relative content) on coating performance, we have developed and optimized ECs formulated with SB as the antifungal ingredient and different ratios of pregelatinized potato starch (PPS), glyceryl monostearate (GMS) and glycerol as hydrophobic and plasticizer components to maintain the physicochemical and sensory quality of 'Orri' mandarins during storage (Soto-Muñoz et al., 2021). From that research, two antifungal ECs were selected as promising treatments to maintain quality, reduce decay and extend postharvest life of mandarins.

The objective of the present study was to assess the efficacy of the optimized antifungal PPS-based ECs containing SB for control of GM and BM on mandarins, 
oranges and lemons. Curative activity of the ECs was assessed on fruit artificially inoculated with the postharvest pathogens and stored at either $20^{\circ} \mathrm{C}$ or commercial low temperatures $\left(5^{\circ} \mathrm{C}\right.$ for mandarins and oranges, $12^{\circ} \mathrm{C}$ for lemons).

\section{MATERIALS AND METHODS}

Abbreviations used in this paper are presented in Table 1.

\section{Fruit}

Experiments were conducted with 'Orri' mandarins (Citrus reticulata Blanco), 'Valencia' oranges (Citrus sinensis (L.) Osbeck) and 'Fino' lemons (Citrus limon (L.) Osbeck). Commercially mature fruit were collected from citrus orchards in the Valencia area (Spain), and were used the same day or stored $\left[5^{\circ} \mathrm{C}, 90 \%\right.$ relative humidity $(\mathrm{RH})$ ] for up to 1 week before use. No commercial postharvest treatments were applied to the fruit before the experiments. Fruit were selected for uniformity of size and shape, and diseased or mechanically damaged fruit were discarded. Selected fruit were surface disinfected (4-min dips in $0.5 \%$ sodium hypochlorite solution), rinsed with tap water, allowed to air dry at room temperature, and then randomized before each experiment.

\section{Fungal inoculations}

The fungus strains NAV-7 of $P$. digitatum and MAV1 of $P$. italicum were obtained from decayed citrus fruit

Table 1. Abbreviations used in this paper.

\begin{tabular}{ll}
\hline Abbreviation & \multicolumn{1}{c}{ Definition } \\
\hline GM & Green mould \\
BM & Blue mould \\
ECs & Edible coatings \\
GRAS & Generally recognized as safe \\
SB & Sodium benzoate \\
HPMC & Hydroxypropyl methylcellulose \\
PPS & Pregelatinized potato starch \\
GMS & Glyceryl monostearate \\
RH & Relative humidity \\
PDA & Potato dextrose agar \\
\hline
\end{tabular}

from local packhouses in the Valencia region. These strains were isolated, identified and maintained in the culture collection of postharvest pathogens of the IVIA CTP, after being selected for their aggressiveness and uniform behaviour on fruit of the most commercially important citrus cultivars. These isolates were deposited in the Spanish Type Culture Collection (CECT, University of Valencia, Valencia, Spain) with the accession numbers CECT 21108 for NAV-7 and CECT 21109 for $\mathrm{MAV}-1$. Prior to the experiments, the two isolates were incubated on potato dextrose agar (PDA) (Scharlab S.L.) in Petri dishes at $25^{\circ} \mathrm{C}$ for $7-14 \mathrm{~d}$.

For fruit inoculations, conidia from 7- to 14-d-old cultures of $P$. digitatum or $P$. italicum were taken from the PDA surfaces with sterilized inoculation loops and each transferred to a sterile aqueous solution of $0.05 \%$ Tween 80 (Panreac-Química S.A.). Conidium suspensions were then filtered through two layers of cheesecloth. Conidium numbers in suspensions were measured with a hemocytometer, and dilutions with sterile water were made to obtain an inoculum density of $10^{5}$ conidia $\mathrm{mL}^{-1}$. Each pathogen was wound-inoculated onto different sets of fruit. For each inoculation, the tip of a stainless steel rod ( $1 \mathrm{~mm}$ wide, $2 \mathrm{~mm}$ long) was immersed in the conidium suspension and then inserted in the fruit rind. Each fruit was inoculated at one point in the equatorial zone. Inoculated fruit were kept at $20^{\circ} \mathrm{C}$ and $90 \%$ $\mathrm{RH}$ for $24 \mathrm{~h}$ before application of fruit coatings.

\section{Preparation of edible fruit coatings}

The ECs were prepared by combining PPS as biopolymer (Quimidroga, S.A.), GMS as lipidic component (Italmatch Chemicals Spa) and glycerol as plasticizer (Panreac-Química S.A.) suspended in water. SB (SigmaAldrich Química S.A.) was added as antifungal GRAS salt in the formulations at $2 \%(\mathrm{w} / \mathrm{v})$. These ingredients were combined in different proportions to prepare four different ECs designated as F10, F6, F10/SB and F6/SB based on the optimized stable emulsions described by Soto-Muñoz et al. (2021), where F10 and F6 were the PPS-GMS-based ECs formulated without GRAS salt and $\mathrm{F} 10 / \mathrm{SB}$ and $\mathrm{F} 6 / \mathrm{SB}$ were the same ECs formulated with $2 \% \mathrm{SB}$. The proportions of each component and the characteristics of these ECs are detailed in Table 2. In all formulations, sunflower lecithin (LEC) and diacetyl tartaric acid esters of mono-diglycerides (DATEM) (Lasenor S.A.) were also incorporated as emulsifiers at the ratio GMS:emulsifier of 2:1 (dry basis, db).

For each preparation, a PPS solution $(5 \%, w / w)$ was first stirred at $65^{\circ} \mathrm{C}$ for $30 \mathrm{~min}$, and then kept under magnetic stirring at $25^{\circ} \mathrm{C}$ overnight. The required 
Table 2. Composition and characteristics of the edible fruit coatings evaluated in this study.

\begin{tabular}{lrrrr}
\hline \multirow{2}{*}{$\begin{array}{l}\text { Composition and } \\
\text { characteristics }^{\mathrm{a}}\end{array}$} & F10 & F6 & F10/SB & F6/SB \\
\cline { 2 - 5 } & - & - & 2.0 & 2.0 \\
\hline SB concentration (\%, w.b.) & 3.9 & 3.5 & 5.9 & 5.5 \\
Solid content (\%) & 48.3 & 28.6 & 32.0 & 18.2 \\
PPS (\%, d.b.) & 13.2 & 28.6 & 8.8 & 18.2 \\
GMS (\%, d.b.) & 25.2 & 14.3 & 16.7 & 9.1 \\
Glycerol (\%, d.b.) & 3.3 & 3.3 & 5.8 & 5.4 \\
pH & 55.1 & 48.6 & 33.6 & 11.2 \\
Viscosity (cP) & & & & \\
\hline
\end{tabular}

a SB, sodium benzoate; PPS, pregelatinized potato starch; GMS, glyceryl monostearate (GMS); w.b., wet basis; d.b., dry basis.

amount of SB aqueous solution (10\% w/w), the emulsifiers and water were then added to the PPS solution, GMS and glycerol and the resulting emulsion was heated to $90^{\circ} \mathrm{C}$. Once the compounds were melted, samples were homogenized using a high-shear probe mixer (UltraTurrax IKA ${ }^{\oplus}$ model T25; IKA-Werke) for $1 \mathrm{~min}$ at 12,000 $\mathrm{rpm}$ followed by $3 \mathrm{~min}$ at 22,000 rpm. Emulsions were then cooled under agitation to a temperature below $25^{\circ} \mathrm{C}$ by placing them in an ice/waterbath under constant agitation for $25 \mathrm{~min}$. The emulsions were kept overnight at $5^{\circ} \mathrm{C}$ before use.

\section{Assessment of curative activity of fruit coatings}

'Orri' mandarins and 'Fino' lemons were artificially inoculated with each pathogen (as above) and incubated at $20^{\circ} \mathrm{C}$ for $24 \mathrm{~h}$. Inoculated fruit were then individually treated by immersion $\left(10 \mathrm{~s}\right.$ at $\left.20^{\circ} \mathrm{C}\right)$ in relevant coating emulsions, drained and allowed to air-dry at room temperature. Curative activity of ECs was assessed since the disease control treatments were applied to already infected fruit. Treatments applied were: control $=$ uncoated (immersion in water at $20^{\circ} \mathrm{C}$ for $10 \mathrm{~s}$ ); F10 coating; F6 coating; SB (immersion in 2\% (w/v) SB aqueous solution at $20^{\circ} \mathrm{C}$ for $10 \mathrm{~s}$ ); F10/SB coating, or F6/SB coating. For each pathogen, each treatment was applied to four replicates of five fruit each. Treated fruit were randomly placed on cavity sockets in plastic trays and incubated at $20^{\circ} \mathrm{C}$ and $90 \% \mathrm{RH}$. Incidence of GM and $\mathrm{BM}$ were assessed as the percentage of decayed fruit, and disease severity was determined as individual lesion diameter $(\mathrm{mm})$. All wounds, including asymptomatic wounds $($ diam. $=0 \mathrm{~mm})$, were considered. Disease inci- dence and severity were assessed after 4 and $7 \mathrm{~d}$ incubation at $20^{\circ} \mathrm{C}$. Experiments were repeated once, and average data are presented.

\section{Effectiveness of fruit coatings during cold storage}

'Orri' mandarins, 'Valencia' oranges and 'Fino' lemons were inoculated and treated as described above (the six different treatments were applied to each of the three fruit species). For each host and disease (GM or BM), each treatment was applied to four replicates of ten fruit each. Treated fruit were randomly placed on cavity sockets in plastic trays and then cold-stored in recommended commercial conditions. The mandarins and oranges were stored at $5^{\circ} \mathrm{C}$, and the lemons were kept at $12^{\circ} \mathrm{C}$ to avoid chilling injury (Ladaniya, 2008; Zacarias et al., 2020). RH was $90 \%$ in all cases. Incidence and severity of GM and BM were assessed as described above. These parameters were evaluated for mandarins after 2, 3, 4 and 5 weeks of cold storage, for oranges after 4, 6 and 10 weeks, and for lemons after 1, 2 and 3 weeks. Every trial was conducted twice, and average data are presented.

\section{Statistical analyses}

Data from all experiments were subjected to analysis of variance (ANOVA). Since experiment was not a statistically significant factor, means of repeated experiments are presented. Disease incidence proportions were arcsine square root transformed to improve the homogeneity of variances. Where appropriate, Fisher's Protected Least Significant Difference (LSD) test, at the 95\% level of confidence $(P=0.05)$, was used for means separation. Non-transformed means are presented. All statistical analyses were carried out using Statgraphics Centurion XVII software (Statgraphics Technologies Inc.).

\section{RESULTS}

\section{Curative activity of fruit coatings}

The ECs formulated without SB (F6 and F10) did not exhibit activity against GM and $\mathrm{BM}$ on 'Orri' mandarins incubated for 4 and $7 \mathrm{~d}$ at $20^{\circ} \mathrm{C}$, with similar or greater mean incidence and severity values in all cases than those for uncoated control fruit (Figure 1). In contrast, the ECs formulated with SB (F6/ $\mathrm{SB}$ and $\mathrm{F} 10 / \mathrm{SB}$ ) significantly reduced the incidence and 


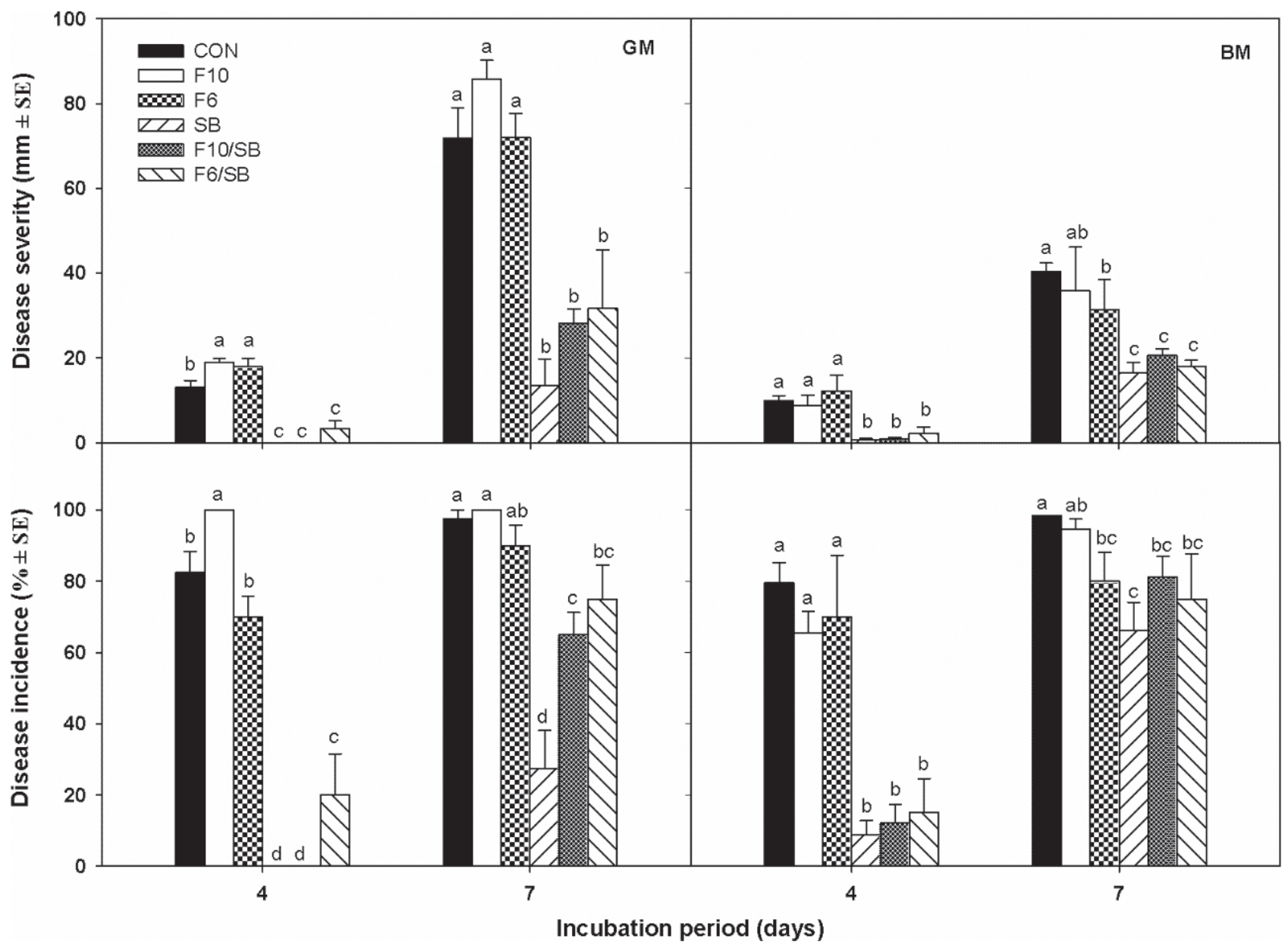

Figure 1. Mean severity and incidence of green mould (GM) or blue mould (BM) on 'Orri' mandarins artificially inoculated, respectively, with Penicillium digitatum or P. italicum, then coated $24 \mathrm{~h}$ later and incubated for 4 and $7 \mathrm{~d}$ at $20^{\circ} \mathrm{C}$ and $90 \% \mathrm{RH}$. Treatments applied were: control $(\mathrm{CON})=$ uncoated (immersion in water), F10 coating, F6 coating, 2\% sodium benzoate (SB) aqueous solution (w/v), F10/SB coating, or F6/SB coating (see Table 2 for coating composition). For each disease and incubation period, columns accompanied by different letters are significantly different (Fisher's protected LSD test; $P<0.05$ ). Vertical lines above columns indicate standard errors. Incidence values were arcsine-transformed before statistical analyses. Non-transformed means are shown.

severity of GM and BM compared to uncoated control fruit after $4 \mathrm{~d}$ of incubation. Effectiveness of these antifungal ECs to reduce incidence and severity of GM and BM was similar to that obtained with the SB aqueous treatment. After $7 \mathrm{~d}$, incidence and severity increased significantly in all cases. The antifungal ECs, F6/SB and F10/SB, reduced the severity of GM and $\mathrm{BM}$, with severity reductions of $50-80 \%$ with respect to uncoated control fruit, and no significant differences were observed with the SB treatment. However, although both antifungal ECs reduced the incidence of GM, they were less effective than SB in aqueous solution, with reductions of approx. $30 \%$ for coated fruit in comparison to $70 \%$ for SB-treated fruit. Similar reductions of $20-30 \%$ were observed for BM incidence on coated 'Orri' mandarins after $7 \mathrm{~d}$ of storage, but in this case without statistically significant differences from the SB treatment.

On 'Fino' lemons incubated up to $7 \mathrm{~d}$ at $20^{\circ} \mathrm{C}, \mathrm{F} 6$ and F10 (without $\mathrm{SB}$ ) did not reduce the incidence and severity of GM and BM compared to uncoated control fruit, with few exceptions (Figure 2). For example, incidence reductions of approx. 20-30\% were obtained with F6 against BM. However, these reductions were always less than those obtained with the antifungal ECs containing SB or the SB aqueous solution, showing that the PPS-based matrices without GRAS salt exhibited no relevant antifungal activity. After $7 \mathrm{~d}$ of incubation, the incidence and severity of GM was nil on fruit coated with F10/SB or treated with 2\% SB aqueous solution, 


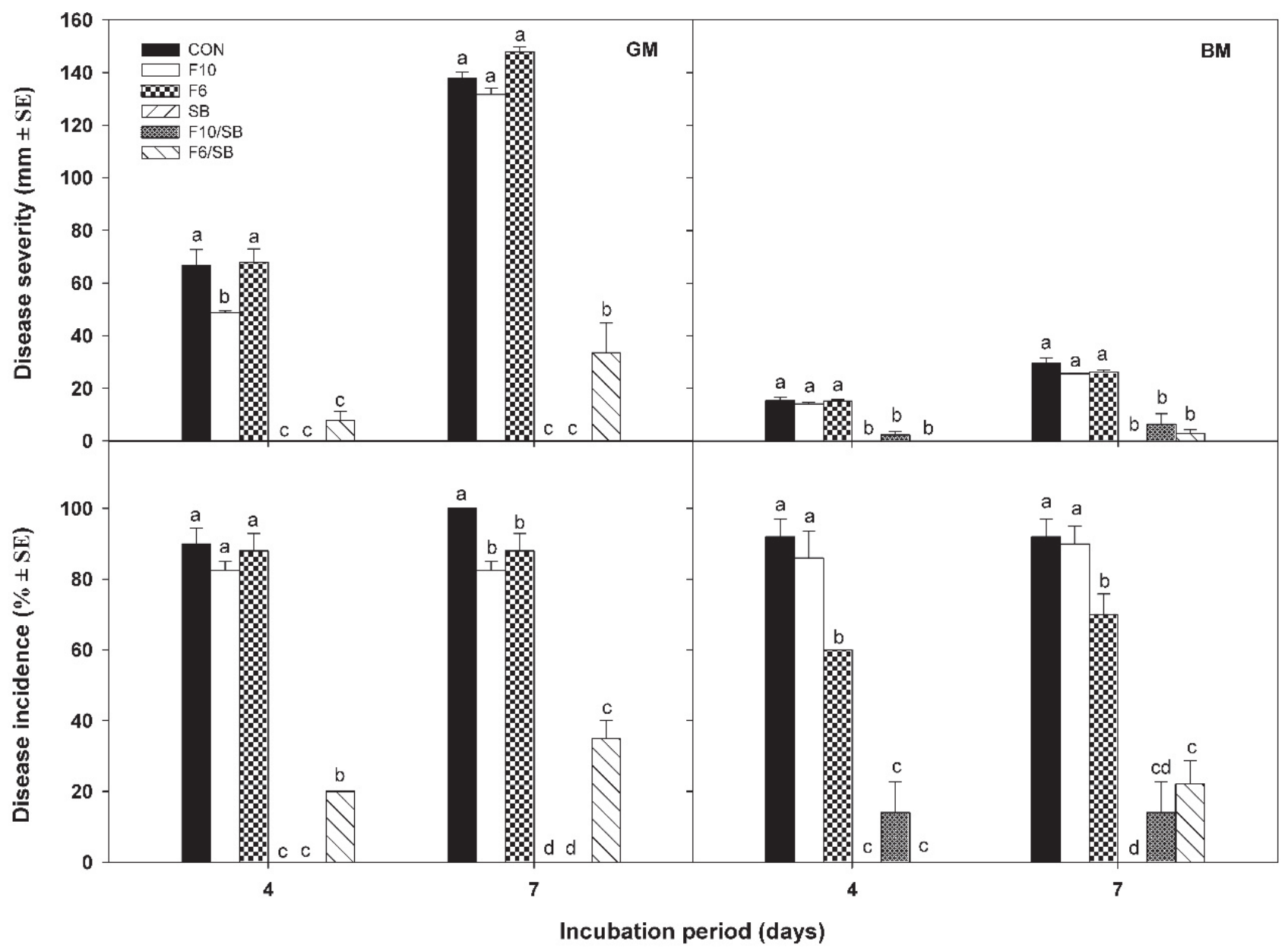

Figure 2. Mean severity and incidence of green mould (GM) or blue mould (BM) on 'Fino' lemons artificially inoculated, respectively, with Penicillium digitatum or P. italicum, then coated $24 \mathrm{~h}$ later and incubated for 4 and $7 \mathrm{~d}$ at $20^{\circ} \mathrm{C}$ and $90 \% \mathrm{RH}$. Treatments applied were: control $(\mathrm{CON})=$ uncoated (immersion in water), F10 coating, F6 coating, 2\% sodium benzoate (SB) aqueous solution (w/v), F10/SB coating, or F6/SB coating (see Table 2 for coating composition). For each disease and incubation period, columns accompanied by different letters are significantly different (Fisher's protected LSD test; $P<0.05$ ). Vertical lines above columns indicate standard errors. Incidence values were arcsine-transformed before statistical analyses. Non-transformed means are shown.

whereas the F6/SB coating reduced incidence of GM by $65 \%$ and severity by $75 \%$, compared to control fruit. For BM, the reductions after $4 \mathrm{~d}$ of both incidence and severity were $85-100 \%$ on coated lemons and lemons immersed in $2 \%$ SB solution, without statistically significant differences among these treatments. These reductions were maintained after $7 \mathrm{~d}$ of incubation, although the reduction in $\mathrm{BM}$ incidence for the lemons coated with $\mathrm{F} 6 / \mathrm{SB}$ and F10/SB was less than for the fruit treated with aqueous SB, which completely inhibited GM development. Nevertheless, these antifungal coatings reduced the incidence of BM by approx. $85 \%$ compared to control fruit.

In every test, no phytotoxicity was observed on the rind of treated fruit.

\section{Effectiveness of fruit coatings during cold storage}

The effectiveness of treatments applied for control of $\mathrm{GM}$ and $\mathrm{BM}$ on 'Orri' mandarins cold-stored at $5^{\circ} \mathrm{C}$ for up to 5 weeks is illustrated in Figure 3. The ECs without SB (F6 and F10) did not control either GM or BM. In contrast, the applications of $\mathrm{SB}$, alone as aqueous solution or incorporated into ECs, reduced GM severity, achieving reductions of $80-100 \%$ after 2 weeks, $90-100 \%$ after 3 weeks, $75-95 \%$ after 4 weeks, and $70-90 \%$ after 5 weeks, compared to the uncoated control. On the other hand, F10/SB and SB treatments reduced GM incidence, with reductions of $95-100 \%$ after 2 weeks, $60-80 \%$ after 4 weeks, and 55-65\% after 5 weeks, compared to control fruit, without statistically significant differences between 


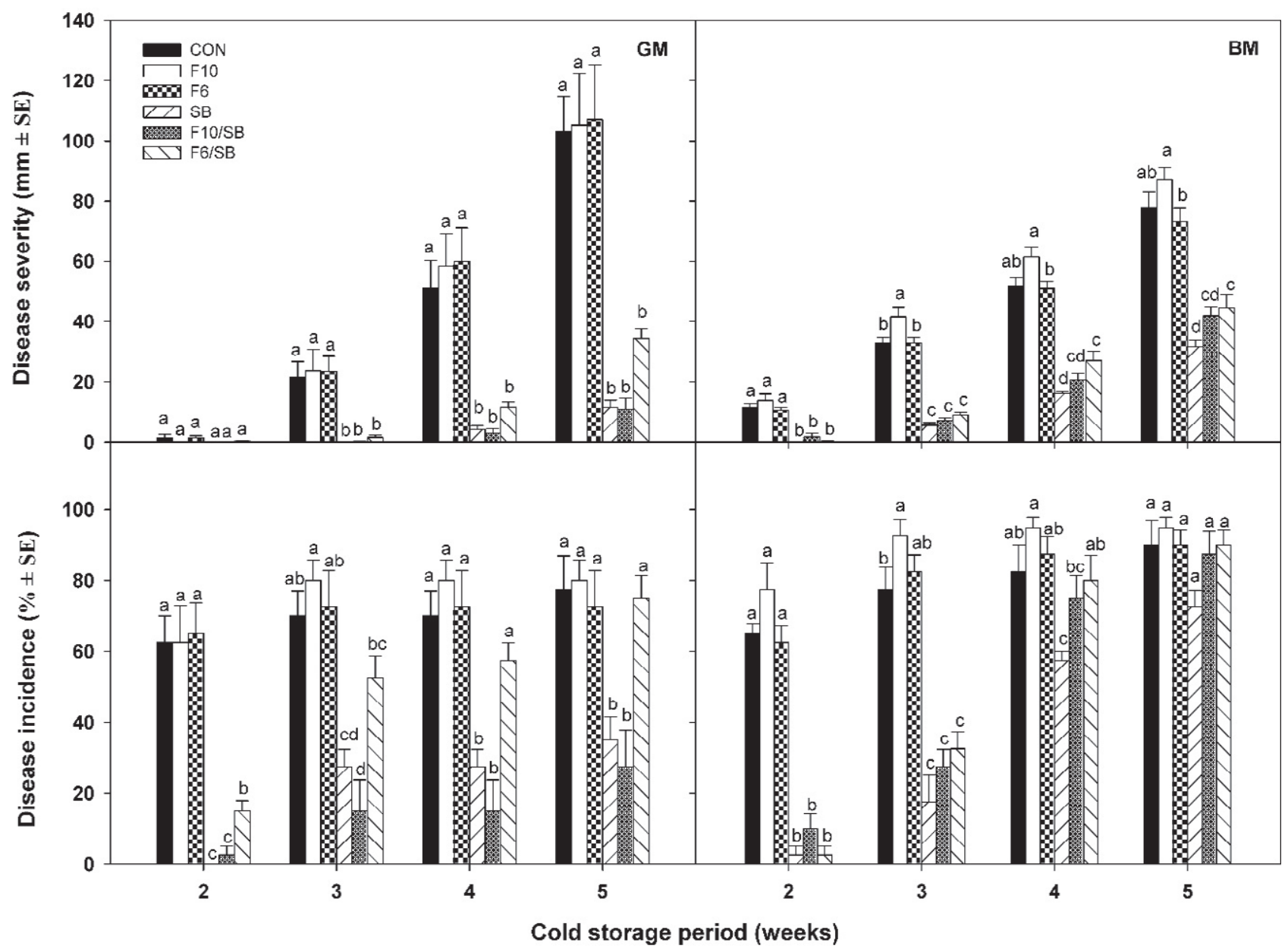

Figure 3. Mean severity and incidence of green mould (GM) or blue mould (BM) on 'Orri' mandarins artificially inoculated, respectively, with Penicillium digitatum or P. italicum, then coated $24 \mathrm{~h}$ later and cold-stored for 2, 3, 4 and 5 weeks at $5^{\circ} \mathrm{C}$ and $90 \% \mathrm{RH}$. Treatments applied were: control $(\mathrm{CON})=$ uncoated (immersion in water), F10 coating, F6 coating, 2\% sodium benzoate (SB) aqueous solution (w/v), F10/SB coating, or F6/SB coating (see Table 2 for coating composition). For each disease and incubation period, columns accompanied by different letters are significantly different (Fisher's protected LSD test; $P<0.05$ ). Vertical lines above columns indicate standard errors. Incidence values were arcsine-transformed before statistical analyses. Non-transformed means are shown.

these treatments. Effectiveness of F6/SB in reducing GM incidence was less than that of $\mathrm{F} 10 / \mathrm{SB}$ or $\mathrm{SB}$, and after 4 weeks of cold storage there were no statistically significant differences between these treatments and the experimental controls. Similar results were observed for BM severity. Only the ECs or the SB aqueous solution reduced BM severity on 'Orri' mandarins during cold storage, and these reductions at the end of the storage period were greater on SB-treated fruit (60\% reduction) than on coated fruit (40\% reduction). For BM, the ECs reduced disease incidence during the first 3 weeks of cold storage, without statistically significant differences between coated- and SB-treated fruit, whereas, after 4 weeks, only the SB aqueous solution reduced BM incidence (up to $30 \%$ ), and this effectiveness disappeared after 5 weeks of storage.
Data of severity and incidence of GM and BM on coated and uncoated 'Valencia' oranges stored for up to 10 weeks at $5^{\circ} \mathrm{C}$ are summarized in Figure 4. Similar to results for mandarins, only the treatments containing $\mathrm{SB}$, alone or incorporated to the PPS-based ECs, reduced GM and BM on 'Valencia' oranges. In general, in all cases, the effectiveness of the fruit coatings was similar to that from the SB aqueous treatment. Thus, for example, after 10 weeks of storage, reductions in severity were $85-90 \%$ for GM and $65-75 \%$ for BM, and reductions of incidence were $30-50 \%$ for GM and $20-40 \%$ for BM.

On 'Fino' lemons, incidence of GM and BM on uncoated control samples and fruit coated with F10 and $\mathrm{F} 6$ (without $\mathrm{SB}$ ) were $100 \%$ after 1 week of storage at $12^{\circ} \mathrm{C}$ (Figure 5). The treatments $\mathrm{F} 6 / \mathrm{SB}, \mathrm{F} 10 / \mathrm{SB}$ and 


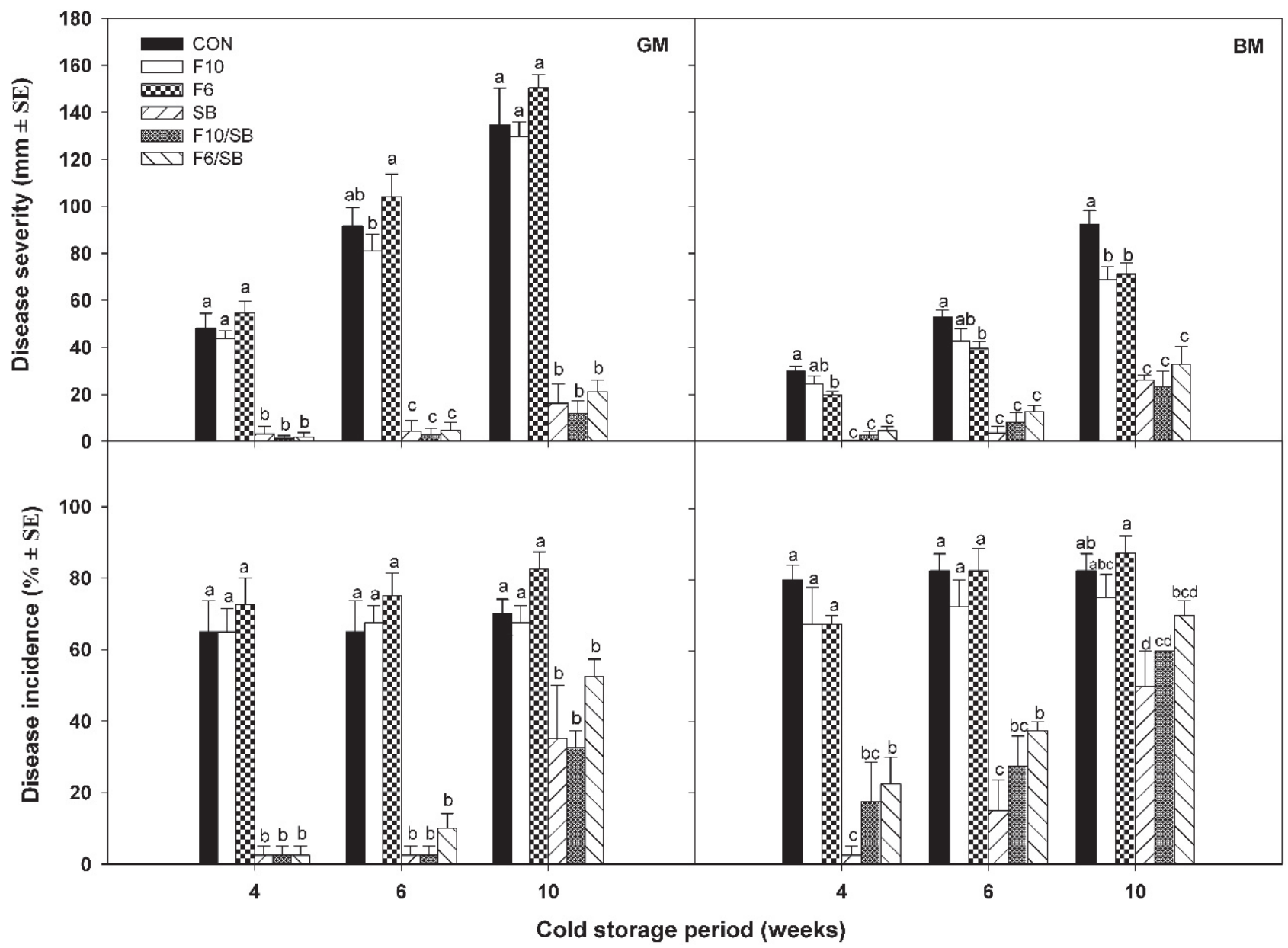

Figure 4. Mean severity and incidence of green mould (GM) or blue mould (BM) on 'Valencia' oranges artificially inoculated, respectively, with Penicillium digitatum or P. italicum, then coated 24 h later and cold-stored for 4,6 and 10 weeks at $5^{\circ} \mathrm{C}$ and $90 \% \mathrm{RH}$. Treatments applied were: control $(\mathrm{CON})=$ uncoated (immersion in water), F10 coating, F6 coating, 2\% sodium benzoate (SB) aqueous solution (w/v), F10/SB coating, or F6/SB coating (see Table 2 for coating composition). For each disease and incubation period, columns accompanied by different letters are significantly different (Fisher's protected LSD test; $P<0.05$ ). Vertical lines above columns indicate standard errors. Incidence values were arcsine-transformed before statistical analyses. Non-transformed means are shown.

SB reduced incidence and severity of GM and BM during the 3-week storage period compared to control fruit and fruit treated with ECs without GRAS salt. Among the treatments, F6/SB was the least effective coating against GM, with reductions of $35 \%$ in incidence and $40 \%$ in severity after 3 weeks. In contrast, the coating F10/SB and SB aqueous solution reduced GM incidence by $60-65 \%$ and severity by $75-80 \%$. Reduction of BM severity ranged from $90-100 \%$ after 1 week of storage, and from $50-70 \%$ at the end of the 3-week storage period on lemons treated with $\mathrm{F} 6 / \mathrm{SB}, \mathrm{F} 10 / \mathrm{SB}$ or $\mathrm{SB}$, without statistically significant differences among these treatments. These treatments also reduced BM incidence during storage, and the $\mathrm{SB}$ treatment was more effective than F6/SB and F10/SB treatments after 1 and 2 weeks.
However, after 3 weeks, all three treatments were equally effective against $\mathrm{BM}$, reducing incidence of the disease by $30-40 \%$ compared to control fruit.

Irrespective of the citrus species and the storage conditions, none of the treatments was visibly phytotoxic.

\section{DISCUSSION}

SB is regarded as a GRAS salt by regulations in many countries, and this compound is widely used as a food preservative with broad spectrum activity against yeasts and moulds (Chipley, 2005). Furthermore, the compound is effective for controlling postharvest Penicillium decay of citrus fruit (Montesinos-Herrero et 


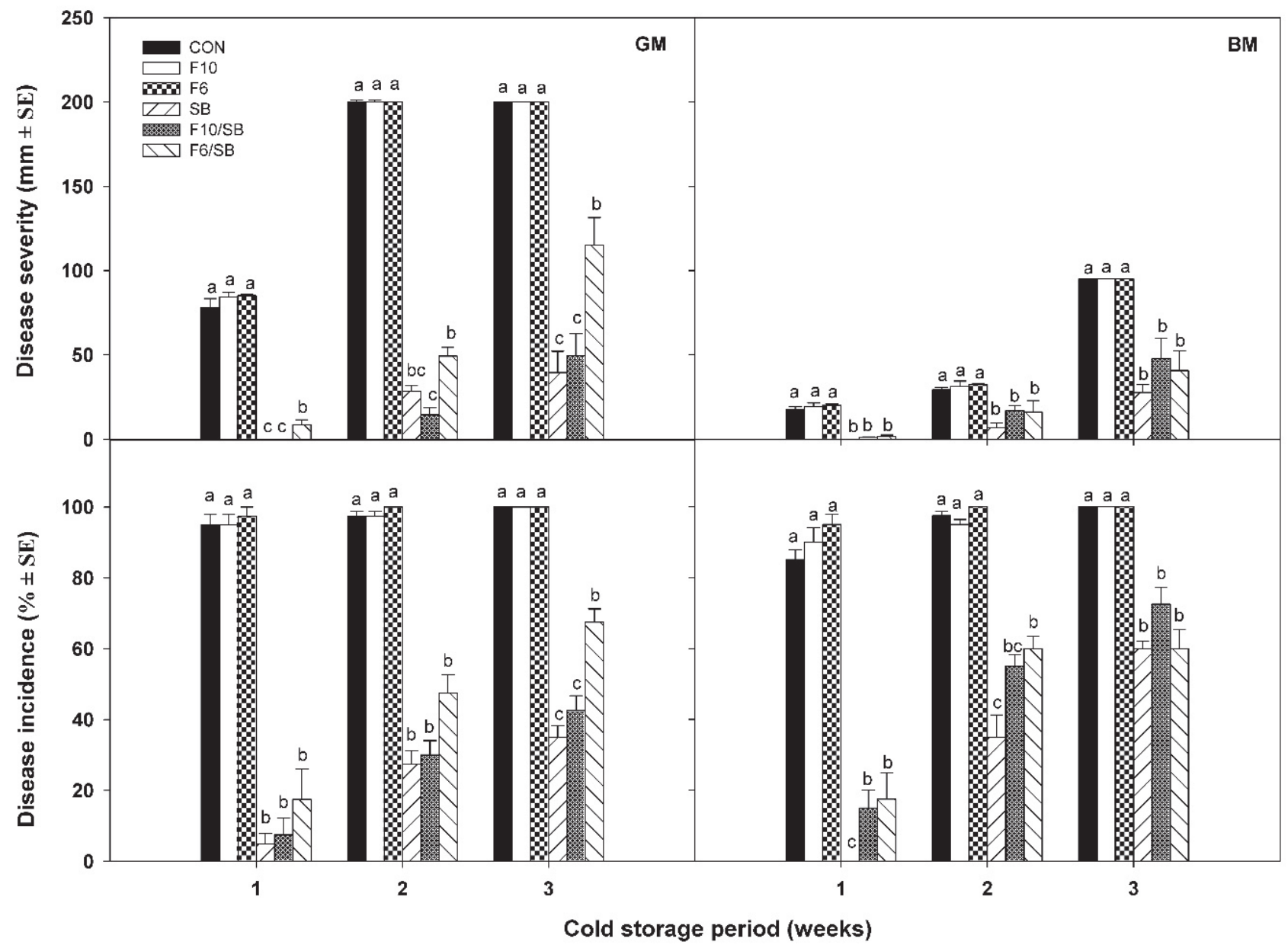

Figure 5. Mean severity and incidence of green mould (GM) or blue mould (BM) on 'Fino' lemons artificially inoculated, respectively, with Penicillium digitatum or P. italicum, then coated $24 \mathrm{~h}$ later and cold-stored for 7,14 and $21 \mathrm{~d}$ at $12^{\circ} \mathrm{C}$ and $90 \%$ RH. Treatments applied were: control $(\mathrm{CON})=$ uncoated (immersion in water), F10 coating, F6 coating, 2\% sodium benzoate (SB) aqueous solution (w/v), F10/SB coating, or F6/SB coating (see Table 2 for coating composition). For each disease and incubation period, columns accompanied by different letters are significantly different (Fisher's protected LSD test; $P<0.05$ ). Vertical lines above columns indicate standard errors. Incidence values were arcsine-transformed before statistical analyses. Non-transformed means are shown.

al., 2016; Palou, 2018). The present study has evaluated incorporation of SB at a concentration of $2 \%$ as an ingredient of novel PPS-GMS-based ECs, after optimization in previous research by response surface methodology of fruit coating ingredients for improving the postharvest quality of 'Orri' mandarins (Soto-Muñoz et al., 2021). The results presented here demonstrate the effectiveness of these antifungal PPS-GMS-based ECs for control of GM and BM on fruits of three citrus species. This is the first report on the effectiveness of these types of ECs for control of major citrus postharvest diseases.

In general, the functionality of ECs based on polysaccharide matrices that do not exert direct inhibitory effects against spoilage microorganisms, in contrast to other ECs such as chitosan or Aloe vera gels, can be improved by incorporation of additional antifungal ingredients such as GRAS salts or food-grade preservatives. In these amended coatings, incorporation of the antifungal ingredients may facilitate slow diffusion of active ingredients from the matrices, regulating temporal and spatial release and facilitating continuous and effective contact with target pathogens, thus enhancing their effectiveness (Mehyar et al., 2011). These incorporations may also reduce possible phytotoxicity risks or adverse sensory properties derived from the direct application of the antifungal ingredient (Vargas et al., 2008; Palou et al., 2015; Palou, 2018; Sapper and Chiralt, 2018).

Overall, we observed that the coatings without SB did not exhibit activity in any of the conditions tested, confirming that the SB salt was responsible for the effec- 
tiveness of the emulsions F6 and F10 for control of GM and $\mathrm{BM}$ on all three citrus species studied. These results are similar to those from previous studies, which showed that starch-based coatings and films can control pathogenic fungi and bacteria only if the coating matrices are amended with antifungal ingredients. Durango et al. (2006) developed antimicrobial ECs based on yam starch combined with chitosan to control microbial growth on minimally processed carrots, and their results showed that only the ECs containing chitosan reduced growth of pathogenic bacteria. Similarly, Ratnawati and Afifah (2019) reported that arrowroot starch-based films alone did not inhibit foodborne pathogenic bacteria, whereas films amended with the GRAS salts SB, potassium sorbate or calcium propionate did inhibit these organisms. SB was the most effective antibacterial salt, and its antimicrobial effect was related to decreased external $\mathrm{pH}$, alteration of the integrity and permeability of bacteria cell membranes, as well as disturbance of nutrient transport (Lucera et al., 2012). A similar mechanism is likely to be associated with the behaviour of the ECs F6/ SB and F10/SB applied to control GM and BM in citrus fruit. The $\mathrm{pH}$ of the albedo tissue of the citrus fruit rind, the site initially colonized by pathogenic Penicillium spp., is between 5 and 6 , and is influenced by fruit maturity (Widodo et al., 1996; Smilanick et al., 2005). Since the ionization constant of benzoic acid is 4.1, a substantial portion would be protonated and active within wounds of citrus rind. This reduction in intracellular $\mathrm{pH}$ caused by the accumulation of benzoic acid at low external $\mathrm{pH}$ inhibits glycolysis at the stage of phosphofructokinase, causing a fall in ATP and consequent inhibition of cell growth (Krebs et al., 1983; Chipley, 2005; Montesinos-Herrero et al., 2016).

In general, both antifungal ECs equally reduced BM incidence and severity in all three citrus fruit and in the studied storage conditions. However, the emulsion F10/ SB was more effective than F6/SB for control of GM on 'Fino' lemons after incubation at $20^{\circ} \mathrm{C}$ and cold storage, and on 'Orri' mandarins during cold storage. On the other hand, overall, no significant differences were found between the antifungal ECs and the application of $\mathrm{SB}$ as aqueous solution. When a GRAS salt is incorporated into an EC and the coating is applied to fruit, the contact between the salt and the pathogen may be limited, enhanced or unaltered depending on intrinsic and extrinsic factors. These include the emulsion properties ( $\mathrm{pH}$ and viscosity), interaction of the salt with the coating matrix and other components (e.g., emulsifiers and plasticizers), release of the salt from the coating, characteristics of the fruit outer structures, and the storage conditions (Chung et al., 2001; Valencia-Chamorro et al., 2011b; Fagundes et al., 2013; Karaca et al., 2014; Valdés et al., 2017; Guimarães et al., 2019; Martínez-Blay et al., 2020a). Although F6/SB and F10/SB are coating matrices containing the same ingredients, their ingredient proportions are different, which confers different physical properties to the resulting coatings. The emulsion F10/ SB has greater viscosity than F6/SB, which may lead to the formation of a thicker coating for F10/SB than F6/SB (i.e., greater surface solid content), ensuring greater concentration of the GRAS salt per unit fruit surface area. However, these differences may not completely explain why F10/SB was superior to F6/SB for control GM in some experiments, and further research is required to fully define their roles in disease control, particularly regarding the proportions of components used in the F10/SB and F6/SB matrices. The similar effects of the ECs and the SB in aqueous solution for control of GM and $\mathrm{BM}$ suggest that the coating matrix did not limit salt activity, allowing it to act within the infected fruit rind wounds. However, since similar effectiveness of ECs and aqueous SB was also observed on long-term cold-stored fruit, it can also be concluded that the coating matrix played no role in improving the persistence of the aqueous treatment during storage. In contrast, for instance, the study of López et al. (2013) showed that corn starch matrices containing potassium sorbate retained this salt for long periods in polymeric matrices, and actively released the salt to product surfaces, where its action was required during product storage. However, if this salt was applied by immersion or spray methods, its surface antimicrobial action decreased rapidly, so highly concentrated solution was necessary to ensure satisfactory antimicrobial activity.

The present results show that both ECs containing SB and aqueous SB controlled both GM and BM more effectively on lemons than oranges and more effectively on oranges than mandarins. Considering that disease on control fruit was similar for all citrus species tested, these results indicate that variations in the efficacy of the treatments were not only caused by differences in fruit species susceptibility. Disease development is affected by complex interactions between the fruit host, the pathogen and the environment. In the case of diseases caused by wound pathogens, efficacy of an antifungal GRAS salt depends on the amount of salt residue present within wound infection sites occupied by fungi, and on interactions between this residue and rind constituents (Palou et al., 2002; Montesinos-Herrero et al., 2016; Palou, 2018). As previously reported, and depending on the citrus species, such interactions may alter the original toxicity of the salt to the pathogen as a consequence of different rind characteristics, composition or $\mathrm{pH}$ (Valencia- 
Chamorro et al., 2009a; Montesinos-Herrero et al., 2016; Palou et al., 2016). In the present case, the fact that rind $\mathrm{pH}$ is lower in lemons than in oranges and mandarins, and that effectiveness of SB is $\mathrm{pH}$-dependent, increasing the effectiveness of the salt as the $\mathrm{pH}$ decreases within the rind wounds (Palou et al., 2002; Chipley, 2005), may explain why the effectiveness of the treatments was greater on lemons than on the other citrus species. In addition, release of SB from the polymer matrix to the rind wounds in each type of fruit may vary according to the degree of rind resistance to the diffusion of the salt. Therefore, the same ECs may considerably differ in suitability for management of fungal diseases on different fruit species and cultivars (Park, 1999; Palou et al., 2015). Further research may clarify if histological and/or ultrastructural differences between the rinds of lemons, oranges and mandarins can account for different degrees of SB diffusion.

The ECs F6/SB and F10/SB and the SB treatment reduced $\mathrm{GM}$ more than $\mathrm{BM}$, during incubation at $20^{\circ} \mathrm{C}$ and cold storage at $5^{\circ} \mathrm{C}$. Comparing these results with those obtained in previous studies by Valencia-Chamorro et al. (2009a; 2009b; 2011), HPMC-beeswax-based ECs containing SB also controlled GM more effectively than BM on 'Clemenules' and 'Ortanique' mandarins and on 'Valencia' oranges incubated for up to $7 \mathrm{~d}$ at $20^{\circ} \mathrm{C}$ or long-term stored at $5^{\circ} \mathrm{C}$. However, the present results show greater reductions in disease incidence and severity during incubation at $20^{\circ} \mathrm{C}$, which may be due to greater release of SB in the PPS-GMS-based matrix than in the HPMC-beeswax-based matrix. During cold storage, the present results were very similar to those reported for HPMC-based coatings with SB applied to 'Valencia' oranges in equivalent experimental conditions (Valencia-Chamorro et al., 2009a). Moreover, it is well known that at storage at temperatures below $10^{\circ} \mathrm{C}$, $P$. italicum is well adapted, and grows more rapidly than P. digitatum (Smilanick et al., 2020). In general on cold-stored citrus, therefore, the efficacy of postharvest antifungal treatments such as GRAS salts and antifungal ECs as alternatives to synthetic fungicides is less for control BM than GM. Furthermore, the effectiveness of the PPS-GMS-based ECs formulated with SB and the $\mathrm{SB}$ aqueous treatment to control $\mathrm{BM}$ and $\mathrm{GM}$ decreased during the cold storage period, confirming that the effect of the SB salt, either in aqueous solution or incorporated in the ECs, is probably fungistatic rather than fungicidal, in agreement with previous studies (Valencia-Chamorro et al., 2009a, 2011b; MontesinosHerrero et al., 2016). In this sense, and considering the importance of the $\mathrm{pH}$, the salt diffusion properties and the fruit host characteristics, further research on the modes of action of SB and/or ECs containing SB against the pathogens causing citrus GM and BM should focus on the evaluation of actual SB residue levels on fruit, after treatment and during storage. These studies should also consider the role of commercial storage conditions, particularly temperature, on the stability and diffusion of SB on coated and stored fruit, and elucidate the influence of EC emulsion $\mathrm{pH}$ on $\mathrm{SB}$ persistence and effectiveness. Theoretically, an EC emulsion with low $\mathrm{pH}$ would have increased efficacy since a greater portion of the SB would be protonated. Another aspect that deserves further research is the ability of antimicrobial ECs in general and ECs containing SB in particular to kill or inactivate microorganisms of food safety concern, such as Salmonella spp., Listeria spp. and Escherichia coli (Aloui and Khwaldia, 2016). Currently, this is particularly important in citrus packhouses in the United States of America, where sanitation programmes are required to satisfy food safety audits under the Food Safety Modernization Act (FSMA) established by the Food and Drug Administration.

In summary, there is little information available on the addition of antifungal ingredients to starch-based ECs for management of postharvest fruit diseases. Nevertheless, some studies have reported significant antifungal activity when starch-based matrices were amended with antimicrobial ingredients, such as essential oils (Sapper et al., 2019), biocontrol agents (Marín et al., 2016, 2019), natamycin (Yang et al., 2019) and the GRAS salt potassium sorbate (Mehyar et al., 2011). Within this context, the general antifungal activity of starch-based ECs containing antimicrobial compounds outlined in these studies involving a variety of fresh fruit pathosystems is in agreement with the results outlined in the present paper.

The main objective of this work was to assess the antifungal curative activity of PPS-based ECs amended with the GRAS salt SB for control of major postharvest citrus diseases. We have found that PPS-GMS-based ECs reduced GM and BM on 'Orri' mandarins, 'Valencia' oranges and 'Fino' lemons artificially inoculated with $P$. digitatum and $P$. italicum, showing curative activity during fruit incubation in room conditions and postharvest storage at low temperatures. Hence, these new PPS-based ECs containing the GRAS salt SB as antifungal ingredient showed potential as promising treatments to reduce Penicillium citrus decay. Although both ECs gave curative antifungal activity, F10/SB was superior to F6/SB for control of GM and BM on three citrus species incubated at room temperature and also for control of GM on citrus stored at low temperatures. Therefore, PPS-GMS-based ECs, and particularly the coating F10/ 
$\mathrm{SB}$, could be promising means for reducing decay and maintaining fruit quality during long-term cold storage, and thus be effective substitutes for conventional waxes amended with synthetic fungicides.

The information generated in this study provides a basis for further research into the application of antifungal PPS-based ECs on other commercially important citrus cultivars, and their possible combination with other alternative non-polluting methods. This research will assist the establishment of cost-effective multi-strategies to improve the control of Penicillium postharvest decay in citrus packhouses while preserving the overall fruit quality.

\section{ACKNOWLEDGMENTS}

This research was partially funded by the IVIA (Project No. 51910) and the European Union, through the European Regional Development Fund (ERDF) of the Generalitat Valenciana 2014-2020. Dr Lourdes SotoMuñoz postdoctoral programme was supported by a scholarship from the Mexican National Council of Science and Technology (CONACYT-160058-México). Dr Victoria Martínez-Blay's research scholarship is supported by the IVIA and the European Social Fund ('Beca IVIA-FSE' 2018 No. 24). Fontestad S.A. (Montcada, Valencia, Spain) is gratefully acknowledged for providing fruit and technical assistance for this research.

\section{LITERATURE CITED}

Acosta S., Jiménez A., Cháfer M., González-Martínez C., Chiralt A., 2015. Physical properties and stability of starch-gelatin based films as affected by the addition of esters of fatty acids. Food Hydrocolloids 49: 135143. https://doi.org/10.1016/j.foodhyd.2015.03.015

Aloui H., Khwaldia K., 2016. Natural antimicrobial edible coatings for microbial safety and food quality enhancement. Comprehensive Reviews in Food Science and Food Safety 15: 1080-1103. https://doi. org/10.1111/1541-4337.12226

Askarne L., Boubaker H., Boudyach E.H., Ait Ben Aoumar A., 2013. Use of food additives to control postharvest citrus blue mold disease. Atlas Journal of Biology 2: 147-153. https://doi.org/10.5147/ ajb.2013.0128

Chipley J.R., 2005. Sodium benzoate and benzoic acid. In: Antimicrobials in Food (P.M. Davidson, J.N. Sofos, A.L. Branen, ed.), CRC Press, Boca Raton, FL, USA, 11-48. https://doi.org/10.1201/9781420028737
Chung D., Papadakis S.E., Yam K.L., 2001. Release of propyl paraben from a polymer coating into water and food simulating solvents for antimicrobial packaging applications. Journal of Food Processing and Preservation 25: 71-87. https://doi. org/10.1111/j.1745-4549.2001.tb00444.x

Durango A.M., Soares N.F.F., Andrade N.J., 2006. Microbiological evaluation of an edible antimicrobial coating on minimally processed carrots. Food Control 17: 336341. https://doi.org/10.1016/j.foodcont.2004.10.024

Erasmus A., Lennox C.L., Smilanick J.L., Lesar K., Fourie P.H., 2013. Imazalil residue loading and green mould control on citrus fruit as affected by formulation, solution $\mathrm{pH}$ and exposure time in aqueous dip treatments. Postharvest Biology and Technology 77: 43-49. https://doi.org/10.1016/j.postharvbio.2012.11.001

Fagundes C., Pérez-Gago M.B., Monteiro A.R., Palou L., 2013. Antifungal activity of food additives in vitro and as ingredients of hydroxypropyl methylcellulose-lipid edible coatings against Botrytis cinerea and Alternaria alternata on cherry tomato fruit. International Journal of Food Microbiology 166: 391-398. https://doi.org/10.1016/j.ijfoodmicro.2013.08.001

Fagundes C., Palou L., Monteiro A.R., Pérez-Gago M.B., 2015. Hydroxypropyl methylcellulose-beeswax edible coatings formulated with antifungal food additives to reduce alternaria black spot and maintain postharvest quality of cold-stored cherry tomatoes. Scientia Horticulturae 193: 249-257. https://doi.org/10.1016/j. scienta.2015.07.027

Guimarães J.E.R., de la Fuente B., Pérez-Gago M.B., Andradas C., Carbó R.,... Palou L., 2019. Antifungal activity of GRAS salts against Lasiodiplodia theobromae in vitro and as ingredients of hydroxypropyl methylcellulose-lipid composite edible coatings to control Diplodia stem-end rot and maintain postharvest quality of citrus fruit. International Journal of Food Microbiology 301: 9-18. https://doi. org/10.1016/j.ijfoodmicro.2019.04.008

Gunaydin S., Karaca H., Palou L., De La Fuente B., PérezGago M.B., 2017. Effect of hydroxypropyl methylcellulose-beeswax composite edible coatings formulated with or without antifungal agents on physicochemical properties of plums during cold storage. Journal of Food Quality 2017: 8573549. https://doi. org/10.1155/2017/8573549

Janjarasskul T., Krochta J.M., 2010. Edible packaging materials. Annual Review of Food Science and Technology 1: 415-448. https://doi.org/10.1146/annurev. food.080708.100836

Karaca H., Pérez-Gago M.B., Taberner V., Palou, L., 2014. Evaluating food additives as antifungal agents against 
Monilinia fructicola in vitro and in hydroxypropyl methylcellulose-lipid composite edible coatings for plums. International Journal of Food Microbiology 179: 72-79. https://doi.org/10.1016/j.ijfoodmicro.2014.03.027

Krebs H.A., Wiggins D., Stubbs M., Sols A., Bedoya F., 1983. Studies on the mechanism of the antifungal action of benzoate. Biochemical Journal 214: 657-663. https://doi.org/10.1042/bj2140657

Ladaniya M.S., 2008. Physiological disorders and their management. In: Citrus Fruit: Biology, Technology and Evaluation (M. Ladaniya, ed.), Academic Press, Cambridge, MA, USA, 451-463. https://doi. org/10.1016/B978-012374130-1.50019-X

López O. V., Giannuzzi L., Zaritzky N.E., García M.A., 2013. Potassium sorbate controlled release from corn starch films. Materials Science and Engineering C 33: 1583-1591. https://doi.org/10.1016/j. msec.2012.12.064

Lucera A., Costa C., Conte A., Del Nobile M.A., 2012. Food applications of natural antimicrobial compounds. Frontiers in Microbiology 3: 287. https://doi. org/10.3389/fmicb.2012.00287

Marín A., Cháfer M., Atarés L., Chiralt A., Torres R., ... Teixidó N., 2016. Effect of different coating-forming agents on the efficacy of the biocontrol agent Candida sake CPA-1 for control of Botrytis cinerea on grapes. Biological Control 96: 108-119. https://doi. org/10.1016/j.biocontrol.2016.02.012

Marín A., Plotto A., Atarés L., Chiralt A., 2019. Lactic acid bacteria incorporated into edible coatings to control fungal growth and maintain postharvest quality of grapes. Lactic acid bacteria incorporated into edible coatings to control fungal growth and maintain postharvest quality of grapes. HortScience 54: 337-343. https://doi.org/10.21273/HORTSCI13661-18

Martínez-Blay V., Pérez-Gago M.B., de la Fuente B., Carbó R., Palou L., 2020a. Edible coatings formulated with antifungal GRAS salts to control citrus anthracnose caused by Colletotrichum gloeosporioides and preserve postharvest fruit quality. Coatings 10: 730. https://doi.org/10.3390/coatings 10080730

Martínez-Blay V., Taberner V., Pérez-Gago M.B., Palou L., 2020b. Control of major citrus postharvest diseases by sulfur-containing food additives. International Journal of Food Microbiology 330: 108713. https://doi. org/10.1016/j.ijfoodmicro.2020.108713

Mehyar G.F., Al-Qadiri H.M., Abu-Blan H.A., Swanson B.G., 2011. Antifungal effectiveness of potassium sorbate incorporated in edible coatings against spoilage molds of apples, cucumbers, and tomatoes during refrigerated storage. Journal of Food Science 76: M210-M217. https://doi.org/10.1111/j.17503841.2011.02059.x

Montesinos-Herrero C., Moscoso-Ramírez P.A., Palou L., 2016. Evaluation of sodium benzoate and other food additives for the control of citrus postharvest green and blue molds. Postharvest Biology and Technology 115: 72-80. https://doi.org/10.1016/j.postharvbio.2015.12.022

Moscoso-Ramírez, P.A., Montesinos-Herrero, C., Palou, L., 2013. Characterization of postharvest treatments with sodium methylparaben to control citrus green and blue molds. Postharvest Biology and Technology 77: 128-137. https://doi.org/10.1016/j.postharvbio.2012.10.007

Njombolwana N.S., Erasmus A., Fourie P.H., 2013. Evaluation of curative and protective control of Penicillium digitatum following imazalil application in wax coating. Postharvest Biology and Technology 77: 102-110. https://doi.org/10.1016/j.postharvbio.2012.11.009

Palou, L., 2014. Penicillium digitatum, Penicillium italicum (Green Mold, Blue Mold), In: Postharvest Decay. Control Strategies (S. Bautista-Baños, ed.), Academic Press, Elsevier Inc., London, UK, 45-102.

Palou, L., 2018. Postharvest treatments with gras salts to control fresh fruit decay. Horticulturae 4: 46. https:// doi.org/10.3390/horticulturae4040046

Palou L., Usall J., Smilanick J.L., Aguilar M.J., Viñas I., 2002. Evaluation of food additives and low-toxicity compounds as alternative chemicals for the control of Penicillium digitatum and Penicillium italicum on citrus fruit. Pest Management Science 58: 459-466. https://doi.org/10.1002/ps.477

Palou L., Valencia-Chamorro S.A., Pérez-Gago M.B., 2015. Antifungal edible coatings for fresh citrus fruit: A review. Coatings 5: 962-986. https://doi. org/10.3390/coatings5040962

Palou L., Ali A., Fallik E., Romanazzi G., 2016. GRAS, plant- and animal-derived compounds as alternatives to conventional fungicides for the control of postharvest diseases of fresh horticultural produce. Postharvest Biology and Technology 122: 41-52. https://doi. org/10.1016/j.postharvbio.2016.04.017

Papoutsis K., Mathioudakis M.M., Hasperué J.H., Ziogas V., 2019. Non-chemical treatments for preventing the postharvest fungal rotting of citrus caused by Penicillium digitatum (green mold) and Penicillium italicum (blue mold). Trends in Food Science \& Technology 86: 479-491. https://doi.org/10.1016/j.tifs.2019.02.053

Park H.J., 1999. Development of advanced edible coatings for fruits. Trends in Food Science \& Technology 10: 254-260. https://doi.org/10.1016/S09242244(00)00003-0 
Ratnawati L., Afifah N., 2019. Effect of antimicrobials addition on the characteristic of arrowroot starchbased films. AIP Conference Proceedings: 2175. https://doi.org/10.1063/1.5134575

Sapper M., Chiralt, A., 2018. Starch-based coatings for preservation of fruits and vegetables. Coatings 8: 152. https://doi.org/10.3390/coatings8050152

Sapper M., Palou L., Pérez-Gago M.B., Chiralt A., 2019. Antifungal starch-gellan edible coatings with thyme essential oil for the postharvest preservation of apple and persimmon. Coatings 9: 333. https://doi. org/10.3390/coatings 9050333

Smilanick J.L., Mansour M.F., Margosan D.A., Mlikota Gabler F., Goodwine, W.R. 2005. Influence of $\mathrm{pH}$ and $\mathrm{NaHCO}_{3}$ on effectiveness of imazalil to inhibit germination of Penicillium digitatum and to control postharvest green mold on citrus fruit. Plant Disease 89: 640-648. https://doi.org/10.1094/PD-890640

Smilanick J.L., Mansour M.F., Gabler F.M., Sorenson D., 2008. Control of citrus postharvest green mold and sour rot by potassium sorbate combined with heat and fungicides. Postharvest Biology and Technology 47: 226-238. https://doi.org/10.1016/j.postharvbio.2007.06.020

Smilanick J.L., Erasmus A., Palou L., 2020. Citrus fruits. In: Postharvest Pathology of Fresh Horticultural Produce (L. Palou, J.L. Smilanick, ed.), CRC Press, Boca Raton, FL, USA, 3-53. https://doi. org/10.1201/9781315209180-1

Soto-Muñoz, L., Palou, L., Argente-Sanchis, M., RamosLópez, M.A., Pérez-Gago, M.B., 2021. Optimization of antifungal edible pregelatinized potato starchbased coating formulations by response surface methodology to extend postharvest life of 'Orri' mandarins. Scientia Horticulturae 288: 110394. https://doi.org./10.1016/j.scienta.2021.110394

Valdés A., Ramos M., Beltrán A., Jiménez, A. Garrigós M.C., 2017. State of the art of antimicrobial edible coatings for food packaging applications. Coatings 7 : 56. https://doi.org/10.3390/coatings7040056.

Valencia-Chamorro S.A., Palou L., Del Río M.A., PérezGago M.B., 2008. Inhibition of Penicillium digitatum and Penicillium italicum by hydroxypropyl methylcellulose-lipid edible composite films containing food additives with antifungal properties. Journal of Agricultural and Food Chemistry 56: 11270-11278. https://doi.org/10.1021/jf802384m

Valencia-Chamorro S.A., Pérez-Gago M.B., Del Río M.A., Palou L., 2009a. Curative and preventive activity of hydroxypropyl methylcellulose-lipid edible composite coatings containing antifungal food additives to con- trol citrus postharvest green and blue molds. Journal of Agricultural and Food Chemistry 57: 2770-2777. https://doi.org/10.1021/jf803534a

Valencia-Chamorro S.A., Pérez-Gago M.B., Del Río M.A., Palou L., 2009b. Effect of antifungal hydroxypropyl methylcellulose (HPMC)-lipid edible composite coatings on postharvest decay development and quality attributes of cold-stored 'Valencia' oranges. Postharvest Biology and Technology 54: 72-79. https://doi. org/10.1016/j.postharvbio.2009.06.001

Valencia-Chamorro S.A., Pérez-Gago M.B., Del Río M.A., Palou L., 2010. Effect of antifungal hydroxypropyl methylcellulose-lipid edible composite coatings on penicillium decay development and postharvest quality of cold-stored 'Ortanique' mandarins. Journal of Food Science 75: S418-S426. https://doi.org/10.1111/ j.1750-3841.2010.01801.x

Valencia-Chamorro S.A., Palou L., Del Río M.A., PérezGago M.B., 2011a. Antimicrobial edible films and coatings for fresh and minimally processed fruits and vegetables: A review. Critical Reviews in Food Science and Nutrition 51: 872-900. https://doi.org/10.1080/10 408398.2010.485705

Valencia-Chamorro, S.A., Palou, L., Del Río, M.A., PérezGago, M.B., 2011b. Performance of hydroxypropyl methylcellulose (HPMC)-lipid edible coatings with antifungal food additives during cold storage of 'Clemenules' mandarins. LWT-Food Science and Technology 44: 2342-2348. https://doi.org/10.1016/j. lwt.2011.02.014

Vargas M., Pastor, C., Chiralt A., McClements D.J., González-Martínez C., 2008. Recent advances in edible coatings for fresh and minimally processed fruits. Critical Reviews in Food Science and Nutrition 48: 496-511. https://doi.org/10.1080/10408390701537344

Widodo S.E., Shiraishi M., Shiraishi S., 1996. Variations of acidity in the peel of acid citrus. I. Acid contents in the flavedo and albedo of acid citrus. Journal of The Faculty of Agriculture Kyushu University 40: 257262. https://doi.org/10.5109/24111

Yang Y., Huan C., Liang X., Fang S., Wang J., Chen J., 2019. Development of starch-based antifungal coatings by incorporation of natamycin/methyl- $\beta$-cyclodextrin inclusion complex for postharvest treatments on cherry tomato against Botrytis cinerea. Molecules 24: 3962. https://doi.org/10.3390/molecules 24213962

Youssef K., Sanzani S.M., Ligorio A., Ippolito A., Terry L.A., 2014. Sodium carbonate and bicarbonate treatments induce resistance to postharvest green mould on citrus fruit. Postharvest Biology and Technology 87: 61-69. https://doi.org/10.1016/j.postharvbio.2013.08.006 
Zacarias L., Cronje P.J., Palou L., 2020. Postharvest technology of citrus fruits. In: The Genus Citrus (M. Talón, M. Caruso, F. Gmitter Jr., ed.), Woodhead Publishing, Elsevier Inc., Sawston, Cambridge, UK, 421-446. https://doi.org/10.1016/b978-0-12-8121634.00021-8 